\title{
Cancer mortality around U.S. nuclear power plants
}

\author{
John F. Hart ${ }^{1 *}$ and Brant Ulsh²
}

*Correspondence: jhartdc@yahoo.com

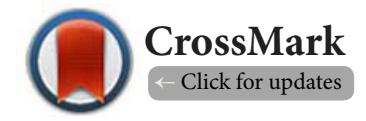

${ }^{1}$ Hart Chiropractic, Greenville, South Carolina, USA.

${ }^{2} \mathrm{M}$.H. Chew and Associates Cincinnati, Ohio, USA.

\begin{abstract}
Introduction: There is concern about cancer risk from living near nuclear power plants (NPP). Different studies yield different results and this study seeks to add to the body of knowledge on the topic.

Methods: Using an ecological design, pair-wise comparisons were made for cancer death rates (CDR) in three county classifications for U.S. NPPs: counties where a NPP was located, counties that bordered the NPP counties, and remaining counties (not NPP counties and not border counties). For purposes of this study, the assumption was that different levels of any radiation released by NPPs would exist in these county classifications, as follows: most in the NPP county, second-most in border counties, and least in the remaining counties.

$\underline{\text { Results: }}$ There were no statistically significant differences between any of the paired comparisons $(\mathrm{p}>0.19)$. Conclusion: The study did not find evidence that living near a nuclear power plant in the U.S. resulted in different cancer death rates among these county classifications. The lack of statistically significant CDR differences among the county classifications is likely related to there being essentially no difference in their radiation levels. However, the study is limited by the lack of inclusion of other cancer-related factors such as smoking rates. Since this is only a preliminary investigation, further study with other research designs is needed to verify this finding.
\end{abstract}

Keywords: Nuclear power plants, cancer death rates, nuclear regulatory commission, radiation

\section{Introduction}

Nuclear power plants release small amounts of nuclear materials during their normal operations [1] which can cause concern about possible increased cancer risk [2]. Various reports provide various findings on the subject of cancer rates around nuclear power plants (NPP). An earlier report found no cancer rate differences for an NPP in California, nor did it find any significant releases in radiation near the plant [3].

A study in Germany in 2008, known as the KiKK study, found increased cancer rates in children living near NPPs [4]. This study has generated significant discussion in the scientific community. Follow-up studies have indicated that the risk decreased over time [5]. Although an explanation for the observed risk is unclear, the most likely explanation may pertain to a yet-tobe-identified infectious agent $[6,7]$. The German Radiological Protection Commission conducted an independent reanalysis of the KiKK study and noted several methodological limitations, and concluded that while the reasons for the observed increased risk remained unclear, multiple confounding factors could have been the cause [8]. Similar reviews have been conducted by Canadian [9] and British [10] regulators, who have reached similar conclusions.

A study in Finland did not find increases in childhood leukemia or adult cancer around NPPs [11]. A study for Switzerland NPPs found "little evidence" for childhood cancer risk [12] and a study in Korea on adults near NPPs revealed no evidence of increased cancer risk [13]. Studies from Great Britain [10,14], Canada [15], and France [16] also did not observe increased cancer risks in the populations living near nuclear power plants. Increased cancer cases that have been reported around NPPs may be due to viruses brought in by the influx of new people into industrial areas that typically would also have NPPs [17]. Other studies, including those for U.S. NPPs suggest increased cancer cases due to the NPP [18-20].

Clearly, further research is indicated on this topic. Thus, the present inquiry studies cancer death rates (CDR) around NPPs 
Hart et al. Epidemiology Reports 2015,

within each U.S. state that has at least one NPP. The idea for this study came from the recent decision by the United States Nuclear Regulatory Commission (NRC) to halt a study of cancer risks of populations near NPPs. The NRC stated that "continuing the work was impractical, given the significant amount of time and resources needed and the agency's current budget constraints" [2]. A previous investigation also studied U.S. NPPs in general but only in regard to childhood cancer incidence [20]. The present study looks at cancer death rates for all ages and all cancer sites and is a preliminary inquiry on this topic (that includes all ages and all cancer sites) for the U.S., setting the stage perhaps for future, more rigorous investigation on the topic. Specifically, the study sought to address the question of whether cancer deaths are higher near NPPs compared to areas away from the plants.

\section{Hypotheses}

The null hypothesis is that cancer rates are the same in all three county classifications while the alternative hypothesis is that at least one of the county classifications has a different CDR from the other two county classifications. Radiation epidemiological studies frequently only consider the possibility that radiation exposure increases risk. Advisory bodies have recommended the integration of radiation biology and epidemiology [21], but how is this recommendation to be put into practice? Radiation biological studies frequently observe nonlinear responses (e.g., thresholds, adaptive responses, and hormetic responses) in biological endpoints, but most radiation epidemiology studies continue to only test the possibility that radiation increases cancer risk, even at low doses, by conducting only one-tailed statistical tests. However, there is another possibility, that CDR may be lower in NPP counties compared to counties farther away. Radiation biology results suggest that epidemiology studies should routinely test the possibility of thresholds, or that low radiation doses may lower cancer risk. To take such possibilities into account, this study conducted two-tailed, rather than one-tailed, statistical tests.

\section{Methods}

\section{Cancer variable}

Age-adjusted cancer (all sites) mortality per 100,000 for U.S. counties was obtained from the U.S. National Cancer Institute (NCl) for all ages, both genders, 2008-2012 [22]. These years were the only option from this source. Since cancer death rates (CDR) tend to vary by race, including by Hispanic origin, a single race was included, one that provided the largest amount of data: white, non-Hispanic.

\section{Nuclear power plant variables}

NPP locations were obtained from the United States Nuclear Regulatory Commission [23]. Ninety-nine plants were located in 30 states where a total of 2,262 counties reported cancer mortality data. Comparison of CDR was made within each of these 30 states among three county classifications: a) coun- ties where the NPP was located ("NPP county"), b) counties that bordered NPP counties via land contact ("border counties"), and c) remaining counties (not NPP counties and not border counties; "remaining counties"). Searches for the NPP counties, and identification of their border counties were conducted with an interactive online map provided by the U.S. Geological Survey [24].

It was assumed that any radiation releases by NPPs will result in largest exposures in NPP counties, second largest in border counties, and least amount in remaining counties. Some NPP counties had more than one NPP. There were 57 NPP counties in the 30 states with NPPs. The 20 states + District of Columbia not having an NPP were not included in the study.

\section{Radiation measurements}

Actual radiation measurements by county are not readily available, and therefore were not included in the study. Thus, the aim of the study was to compare CDR in NPP counties versus counties farther away from the NPPs, with the assumption, for purposes of this study that higher levels of radiation releases exist closer to the NPPs than farther away from the NPPs. It is estimated that a person located at the perimeter of a NPP for a full year would receive approximately 3 milli-rem from that NPP [25].

Weather conditions may carry radioactive particles farther away from NPP counties. In such a case, CDR would be expected to be higher in those areas according to the linear no-threshold hypothesis.

\section{Confounding variables}

Potential confounding variables such as smoking rates by U.S. county, and by race are not readily available. Thus, paired comparisons of CDR were made within each state in an attempt to minimize the effect of these potential confounding variables (that were not included in the study). That is to say, variability of the confounders was considered to be less within each state versus between-states. As an example, smoking rates are likely to be more consistent within a single state, as suggested by their $95 \%$ confidence interval from survey data [26] versus between states. As an example for the latter, in 2011, Minnesota (an NPP state in the present study) had an average smoking rate for whites of $18.2 \%$ (95\% Cl 17.2-19.2) [26]. Alabama on the other hand, also an NPP state in the present study had an average smoking rate for whites of $25.0 \%$ (95\% Cl 23.2-26.7) [26]. Since these two sets of confidence intervals do not overlap for these two states, their smoking rate difference is statistically significant.

\section{Analysis}

Using an ecological design, paired comparisons of mean CDR (over a 5 year period, 2008-2012) by county classification were made within each of the 30 states using the paired $t$ test, in Stata IC 12.1 (StataCorp, College Station, TX), as follows: a) NPP county mean CDR versus border county mean CDR; b) 
Hart et al. Epidemiology Reports 2015,

NPP county mean CDR versus remaining county mean CDR; and c) border county mean CDR versus remaining county mean CDR. This set-up, comparing different people in different regions - within the same state, was thought to warrant paired testing. Such testing (within each state) helped to avoid the greater between-state variability of confounders such as smoking (less variability assumed within a given state). Thus, paired testing (rather than two-sample testing) was considered appropriate for this study design.

Normal distribution may possibly be assumed, even for a single county CDR average, due to the thousands of cancer deaths within the 5 year period in that county, that served as the basis for the mean CDR. However, since the normal distribution assumption may still be in doubt for these data, particularly in the case of one average CDR data point, the Sign test, which does not require a normal distribution, was also performed, in Minitab 16 (Minitab Inc., State College, PA). The Sign test tested the hypothesis that the median difference between matched cancer county classification pairs was zero. A zero difference (e.g., between NPP county cancer and border county cancer) would result in a statistically non-significant $\mathrm{p}$-value, indicating that the paired differences showed as many, or nearly as many positive differences as negative differences. Two-tailed $p$-values were used, and those less than or equal to the conventional alpha level of 0.05 were considered statistically significant.

\section{Results}

Descriptive and summary data are provided in Table 1, CDR differences between county classifications are in Table 2 , and inferential statistics are in Table 3. Mean CDR was: 177.1 per 100,000 (standard deviation [SD] 14.6) in NPP counties; 178.0 per 100,000 (SD 13.2) in border counties; and 180.1 per 100,000 (SD 10.9) in remaining counties. None of the paired tests ( $t$ tests and Sign tests) for these mean CDRs were statistically significant, regardless of the test used, since all p-values were greater than 0.19 (Table 3).

\section{Discussion}

The results of this study suggest that cancer death rates (CDR) were essentially the same, at least for white persons, in nuclear power plant counties, border counties, and remaining counties. The lack of statistically significant CDR differences among the county classifications is likely due to there being essentially no difference in their radiation levels. These results are consistent with a similar, older study done for U.S. counties, published in 1991 [27].

The study is limited by: a) its (ecological) design - where individual exposures are unknown. Nonetheless, ecological designs are common in epidemiological research and often serve as a springboard for other designs. One advantage of the ecological design is that entire populations (e.g., of a state) can be included. Moreover, a number of previous studies on low level radiation and cancer have used the ecological design,
Table 1. Descriptive and summary statistics for $\mathbf{3 0}$ states having at least one nuclear power plant (NPP).

\begin{tabular}{|c|c|c|c|c|c|c|}
\hline State & NPPn & NPPc & NPPnb & NPPcb & RCn & RCc \\
\hline $\mathrm{AL}$ & 2 & 180.7 & 7 & 198.7 & 58 & 191.3 \\
\hline $\mathrm{AZ}$ & 1 & 150.9 & 6 & 149.1 & 8 & 169.1 \\
\hline $\mathrm{AR}$ & 1 & 204.5 & 6 & 199.7 & 68 & 202.4 \\
\hline $\mathrm{CA}$ & 1 & 156.0 & 4 & 164.3 & 52 & 172.5 \\
\hline $\mathrm{CT}$ & 1 & 169.3 & 5 & 160.5 & 2 & 163.8 \\
\hline FL & 2 & 163.2 & 7 & 174.4 & 58 & 190.1 \\
\hline GA & 2 & 189.5 & 16 & 198.6 & 140 & 182.4 \\
\hline IL & 5 & 192.0 & 19 & 184.2 & 78 & 186.9 \\
\hline IA & 1 & 171.3 & 7 & 163.9 & 91 & 169.0 \\
\hline KS & 1 & 198.0 & 7 & 186.4 & 96 & 170.0 \\
\hline LA & 2 & 170.0 & 5 & 176.6 & 57 & 196.2 \\
\hline $\mathrm{MD}$ & 1 & 177.2 & 8 & 176.5 & 15 & 181.6 \\
\hline MA & 1 & 183.7 & 4 & 171.8 & 9 & 172.2 \\
\hline MI & 3 & 184.6 & 6 & 177.6 & 74 & 179.4 \\
\hline MN & 2 & 167.7 & 12 & 159.8 & 73 & 163.7 \\
\hline MS & 1 & 139.4 & 4 & 166.7 & 75 & 190.9 \\
\hline $\mathrm{MO}$ & 1 & 190.3 & 6 & 177.9 & 108 & 193.0 \\
\hline $\mathrm{NE}$ & 2 & 168.7 & 7 & 179.0 & 71 & 160.9 \\
\hline $\mathrm{NH}$ & 1 & 179.4 & 3 & 178.1 & 6 & 174.0 \\
\hline NJ & 2 & 191.8 & 4 & 189.8 & 15 & 174.4 \\
\hline NY & 3 & 175.8 & 10 & 175.9 & 49 & 176.4 \\
\hline $\mathrm{NC}$ & 3 & 159.8 & 18 & 177.1 & 79 & 180.9 \\
\hline $\mathrm{OH}$ & 2 & 186.7 & 7 & 183.5 & 79 & 190.5 \\
\hline PA & 5 & 174.6 & 23 & 179.6 & 39 & 178.8 \\
\hline SC & 3 & 188.4 & 18 & 193.5 & 25 & 176.4 \\
\hline TN & 2 & 188.2 & 9 & 202.3 & 84 & 202.1 \\
\hline TX & 2 & 172.5 & 8 & 181.5 & 220 & 181.3 \\
\hline VA & 2 & 195.0 & 10 & 174.2 & 122 & 180.8 \\
\hline WA & 1 & 173.7 & 5 & 183.0 & 33 & 176.5 \\
\hline WI & 1 & 168.7 & 5 & 154.8 & 65 & 175.3 \\
\hline Mean & 1.9 & 177.1 & 8.5 & 178.0 & 65.0 & 180.1 \\
\hline SD & 1.1 & 14.6 & 5.2 & 13.2 & 45.6 & 10.9 \\
\hline
\end{tabular}

SD: Standard deviation. NPPn: Number of NPP counties (total $\mathrm{n}=57$ ); NPPc: Mean cancer death rate in NPP counties; NPPnb: Number of counties bordering NPP (total $n=256$ ); NPPcb: Mean cancer death rate in border counties; RCn: Number of remaining counties (not NPP and not border; total $\mathrm{n}=1949$ ); RCc: Mean cancer death rate in remaining counties.

showing varying results [28-30]; b) confounding variables, such as smoking and socioeconomic status (SES) were not explicitly considered in the analysis. The inclusion of a single race partially addresses this potential confounder. Another aspect of SES is that NPPs are typically located in rural areas 
Hart et al. Epidemiology Reports 2015,

Table 2. Cancer death rate (CDR) difference between matched pairs of county classifications within each state.

\begin{tabular}{llll}
\hline State & NPP-b & NPP-r & b-r \\
\hline AL & -18.0 & -10.6 & 7.4 \\
AZ & 1.8 & -18.2 & -20.0 \\
AR & 4.8 & 2.1 & -2.7 \\
CA & -8.3 & -16.5 & -8.2 \\
CT & 8.8 & 5.5 & -3.3 \\
FL & -11.2 & -26.9 & -15.7 \\
GA & -9.1 & 7.1 & 16.2 \\
IL & 7.8 & 5.1 & -2.7 \\
IA & 7.4 & 2.3 & -5.1 \\
KS & 11.6 & 28.0 & 16.4 \\
LA & -6.6 & -26.2 & -19.6 \\
MD & 0.7 & -4.4 & -5.1 \\
MA & 11.9 & 11.5 & -0.4 \\
MI & 7.0 & 5.2 & -1.8 \\
MN & 7.9 & 4.0 & -3.9 \\
MS & -27.3 & -51.5 & -24.2 \\
MO & 12.4 & -2.7 & -15.1 \\
NE & -10.3 & 7.8 & 18.1 \\
NH & 1.3 & 5.4 & 4.1 \\
NJ & 2.0 & 17.4 & 15.4 \\
NY & -0.1 & -0.6 & -0.5 \\
NC & -17.3 & -21.1 & -3.8 \\
OH & 3.2 & -3.8 & -7.0 \\
PA & -5.0 & -4.2 & 0.8 \\
SC & -5.1 & 12.0 & 17.1 \\
TN & -14.1 & -13.9 & 0.2 \\
TX & -9.0 & -8.8 & 0.2 \\
VA & 20.8 & 14.2 & -6.6 \\
WA & -9.3 & -2.8 & 6.5 \\
WI & 13.9 & -6.6 & -20.5 \\
\# above zero & 16 & 14 & 11 \\
\# below zero & 14 & 16 & 19 \\
\hline
\end{tabular}

NPP-b is CDR in NPP counties - CDR in border counties. NPP-r is CDR in NPP counties - CDR in remaining counties (not NPP and not border). b-r is CDR in border counties $\mathrm{CDR}$ in remaining counties. As an example, for Alabama, there were 18.0 fewer deaths (per 100,000) in its (two) NPP counties compared to its (seven) counties bordering the NPP counties (in Alabama).

Table 3. Inferential statistics for cancer death rates comparisons by county classification.

\begin{tabular}{lll}
\hline Classification comparison & $\begin{array}{l}\text { Paired } \boldsymbol{t} \text {-test } \\
\text { P-value }\end{array}$ & $\begin{array}{l}\text { Sign test } \\
\text { P-value }\end{array}$ \\
\hline NPP versus border & 0.66 & 0.86 \\
NPP versus remaining & 0.30 & 0.86 \\
Border versus remaining & 0.32 & 0.20 \\
\hline
\end{tabular}

$\mathrm{n}=30$ (NPP states) for each classification with their employees being relatively well-paid and receiving comprehensive benefits packages, including health care insurance. Health care coverage may be a factor in lowering cancer death rates to the extent that they facilitate routine cancer screening and earlier detection; c) lack of actual radiation dose measurements/data; and d) uncertainty whether there was sufficient statistical power in this study to compare radiation levels among the county classifications.

Gender tends to be approximately evenly divided in the general population so this variable was considered accounted for in the study. Other variables considered accounted for in the study are: a) age (since the CDR variable was age-adjusted), b) race (since only a single race was included), and c) CDR variability over time (since death rates over a 5 year period were included, fluctuation of death rates was contained in a single average CDR value).

\section{Conclusion}

This preliminary study did not find any statistically significant differences in cancer death rates near nuclear power plants in the U.S., at least for white persons. The lack of statistically significant CDR differences among the county classifications is likely related to there being essentially no difference in their radiation levels. This study provides a simple example of how to incorporate knowledge from radiation biology studies into radiation epidemiological studies, by simply conducting two-tailed statistical tests instead of arbitrarily limiting the analysis to one-tailed tests. Further study, with actual radiation measurements, explicit accounting of potential confounding variables, and more sophisticated modeling of alternative hypotheses in addition to the conventional linear and linear quadratic dose-responses is indicated.

\section{Competing interests}

The authors declare that they have no competing interests.

Authors' contributions

\begin{tabular}{|l|c|c|}
\hline Authors' contributions & JFH & BU \\
\hline Research concept and design & $\checkmark$ & -- \\
\hline Collection and/or assembly of data & $\checkmark$ & -- \\
\hline Data analysis and interpretation & $\checkmark$ & -- \\
\hline Writing the article & $\checkmark$ & $\checkmark$ \\
\hline Critical revision of the article & $\checkmark$ & $\checkmark$ \\
\hline Final approval of article & $\checkmark$ & $\checkmark$ \\
\hline Statistical analysis & $\checkmark$ & -- \\
\hline
\end{tabular}

\section{Publication history}

Editor: Nicola Luigi Bagazzi, University of Genoa, Italy.

Received: 30-Oct-2015 Final Revised: 02-Dec-2015

Accepted: 17-Dec-2015 Published: 29-Dec-2015

\section{References}

1. U.S. Nuclear Regulatory Commission (NRC). Backgrounder on analysis of cancer risks in populations near nuclear facilities-Phase 2 pilot study. 2014. | Website 
Hart et al. Epidemiology Reports 2015,

2. U.S. Nuclear Regulatory Commission (NRC). NRC ends work on National Academy of Sciences cancer risk pilot study. 2015.

3. Enstrom JE. Cancer mortality patterns around the San Onofre nuclear power plant, 1960-1978. Am J Public Health. 1983; 73:83-92. I PubMed Abstract | PubMed FullText

4. Kaatsch P, Spix C, Schulze-Rath R, Schmiedel S and Blettner M. Leukaemia in young children living in the vicinity of German nuclear power plants. Int J Cancer. 2008; 122:721-6. | Article | PubMed

5. Grosche B. The 'Kinderkrebs in der Umgebung von Kernkraftwerken' study: results put into perspective. Radiat Prot Dosimetry. 2008; 132:198-201. | Article | PubMed

6. Laurier D, Jacob S, Bernier MO, Leuraud K, Metz C, Samson E and Laloi P. Epidemiological studies of leukaemia in children and young adults around nuclear facilities: a critical review. Radiat Prot Dosimetry. 2008; 132:182-90. | Article | PubMed

7. Little J, McLaughlin J and Miller A. Leukaemia in young children living in the vicinity of nuclear power plants. Int J Cancer. 2008; 122:x-xi. | Article I PubMed

8. SSK. Assessment of the "Epidemiological Study on Childhood Cancer in the Vicinity of Nuclear Power Plants" (KiKK Study): Position of the Commission on Radiological Protection (SSK). 2008. I Pdf

9. CNSC. Fact sheet: The KiKK study explained [online]. 2014. | Website

10. COMARE. Committee on Medical Aspects of Radiation in the Environment (COMARE) Fourteenth report, Further consideration of the incidence of childhood leukaemia around nuclear power plants in Great Britain. London, United Kingdom: Health Protection Agency. 2011. I Pdf

11. Heinavaara S, Toikkanen S, Pasanen K, Verkasalo PK, Kurttio P and Auvinen A. Cancer incidence in the vicinity of Finnish nuclear power plants: an emphasis on childhood leukemia. Cancer Causes Control. 2010; 21:587-95. | Article | PubMed Abstract | PubMed FullText

12. Spycher BD, Feller M, Zwahlen M, Roosli M, von der Weid NX, Hengartner $H$, Egger $M$ and Kuehni CE. Childhood cancer and nuclear power plants in Switzerland: a census-based cohort study. Int J Epidemiol. 2011; 40:1247-60. | Article | PubMed Abstract | PubMed FullText

13. Ahn YO and Li ZM. Cancer risk in adult residents near nuclear power plants in Korea - a cohort study of 1992-2010. J Korean Med Sci. 2012; 27:999-1008. | Article | PubMed Abstract | PubMed FullText

14. Bithell JF, Murphy MF, Stiller CA, Toumpakari E, Vincent T and Wakeford $R$. Leukaemia in young children in the vicinity of British nuclear power plants: a case-control study. Br J Cancer. 2013; 109:2880-5. | Article | PubMed Abstract | PubMed FullText

15. Lane R, Dagher E, Burtt J and Thompson PA. Radiation exposure and cancer incidence (1990 to 2008) around nuclear power plants in Ontario, Canada. Journal of Environmental Protection. 2013; 4:888-913. I Article

16. Laurier D, Hemon D and Clavel J. Childhood leukaemia incidence below the age of 5 years near French nuclear power plants. J Radiol Prot. 2008; 28:401-3. | Article | PubMed Abstract | PubMed FullText

17. Janiak MK. Epidemiological evidence of childhood leukaemia around nuclear power plants. Dose Response. 2014; 12:349-64. | Article | PubMed Abstract | PubMed FullText

18. Levin RJ, De Simone NF, Slotkin JF and Henson BL. Incidence of thyroid cancer surrounding Three Mile Island nuclear facility: the 30-year follow-up. Laryngoscope. 2013; 123:2064-71. | Article | PubMed

19. Mangano JJ. Geographic variation in U.S. thyroid cancer incidence and a cluster near nuclear reactors in New Jersey, New York, and Pennsylvania. Int J Health Serv. 2009; 39:643-61. I Article I PubMed

20. Mangano JJ, Sherman J, Chang C, Dave A, Feinberg E and Frimer M. Elevated childhood cancer incidence proximate to U.S. nuclear power plants. Arch Environ Health. 2003; 58:74-82. I Article I PubMed

21. National Research Council of the National Academies of Science (NAS). Health risks from exposure to low levels of ionizing radiation: BEIR VII Phase 2. Washington, DC. 2005. I Website

22. National Cancer Institute ( $\mathrm{NCl}$ ). State cancer profiles. 2015. | Website

23. U.S. Nuclear Regulatory Commission (NRC). Operating nuclear power reactors. 2015. | Website

24. U.S. Geological Survey (USGS). The National Map Viewer. 2015. Website

25. U.S. Nuclear Regulatory Commission (NRC). FAQ about radiation protection. 2012. | Website

26. Centers for Disease Control and Prevention (CDC). Behavioral Risk Factor Surveillance System, 2011. 2015. I Website

27. Jablon S, Hrubec Z and Boice JD, Jr. Cancer in populations living near nuclear facilities. A survey of mortality nationwide and incidence in two states. JAMA. 1991; 265:1403-8. I Article I PubMed

28. Evrard AS, Hemon D, Billon S, Laurier D, Jougla E, Tirmarche M and Clavel J. Childhood leukemia incidence and exposure to indoor radon, terrestrial and cosmic gamma radiation. Health Phys. 2006; 90:569-79. Article I PubMed

29. Auvinen A, Hakama M, Arvela H, Hakulinen T, Rahola T, Suomela M, Soderman B and Rytomaa T. Fallout from Chernobyl and incidence of childhood leukaemia in Finland, 1976-92. BMJ. 1994; 309:151-4. | Article | PubMed Abstract | PubMed FullText

30. Sponslor R and Cameron J. Nuclear shipyard worker study (1980-1988): a large cohort exposed to low-dose-rate gamma radiation. International Journal of Low Radiation. 2005; 1:463-478. | Article

\section{Citation:}

Hart JF and Ulsh B. Cancer mortality around U.S. nuclear power plants. Epidemiol Rep. 2015; 3:6.

http://dx.doi.org/10.7243/2054-9911-3-6 